DIRECT DIAL

DOE/ER/61402--T1

March 4, 1993

DE93 010688

Maria C. Hernandez

Contract Specialist

Department of Energy

San Francisco Field office

1333 Broadway

Oakland, CA 94612

DOE \#DE-FG03-92ER61402

Dear Ms. Hernandez:

Enclosed is the final DOE 8 month Progress Report replacing sent earlier.

Sincerely yours,

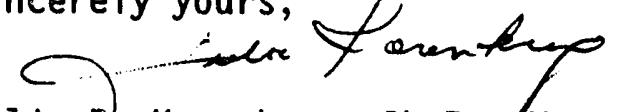

Julie R. Korenberg, Ph.D.,M.D.

Vice Chairman, Pediatric Research

Associate Professor of Pediatrics, UCLA

$$
\begin{gathered}
\text { PACENYED } \\
\text { MR } 2 \text { Y } 1993 \\
\text { O } 3 \text { TI }
\end{gathered}
$$


DOE 8 month Progress Report - April 1. 1992 to December 31.1992

Human cDNA mapping using fluorescence in situ hybridization

DE-FG03-93ER61402

L.R. Korenberg. Ph.D.M.D.

Cedars-Sinai Medical Center

The ultimate goal of this proposal is to create a cDNA map of the human genome. Mapping is approached using the techniques of high resolution fluorescence in situ hybridization (FISH). This technology and the results of its application are designed to rapidly generate whole genome as tool box of expressed sequence to speed the identification of human disease genes. The results of this study are intended to dovetail with and to link the results of existing technologies for creating backbone YAC and genetic maps.

In the first eight months, this approach will generate $60-80 \%$ of the expressed sequence map, the remainder expected to be derived through more long-term, laborintensive, regional chromosomal gene searches or sequencing. The laboratory has made significant progress in the set-up phase, in mapping fetal and adult brain and other cDNAs, in testing a model system for directly linking genetic and physical maps using FISH with small fragments, in setting up a database, and in establishing the validity and throughput of the system. These are detailed below.

\section{SPECIFIC ACCOMPLISHMENTS}

\section{SET-UP PHASE}

Equipment: The major equipment for image analysis has been acquired and will be set up and functioning within 4 weeks. This includes the BDS (Biological Detection Systems) Image analysis system encompassing a Photometrics CCD camera with cooling capacity to -45 degrees $C$, the Zeiss Axiovert with high throughput, a user friendly software package, and guaranteed 1-2 pixel on site registration capacity. Filters appropriate for visual and single color image capture for all necessary dyes are expected within weeks. The institution has granted new space for the equipment, the acquisition of which will increase throughput.

A second work station is being acquired to increase the throughput.

Data Analysis: A SUN work-station has been acquired and is in active use for database searches; all major databases are now on-line with either direct access or updates monthly. Informatics is being handled by Dr. Ray Duncan. A database is being constructed both for data acquisition, storage and sharing with other DOE laboratories. GDB is being reconfigured for direct access by PC by Duncan. This should greatly improve the access of GDB to the overwhelming number of users not at major centers and therefore, the rapid dispersal of genome information to the broader medical and genome community.

Personnel: The last two senior positions are in the process of recruitment.

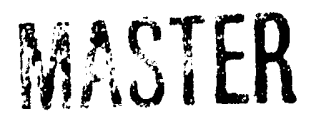

OISTRIBUTION OF THIS NOCUMENT IS INIIMITEG 

HYBRIDIZATION

A. cDNA Mapping.

1. Random Sequencing Projects:

In collaboration with two groups (Venter and Adams; Gatewood), over 120 cDNAs have been mapped by two individuals at approximately $2-3 \mathrm{Mb}$ resolution. In the range of $2 \mathrm{~kb}$, approximately $74 \%$ may be mapped by our current techniques. These cDNAs derive largely from adult and fetal brain libraries. Recently, 30 were mapped from a hydatidiform mole library. The distribution of these closely parallels that of preexisting cDNAs and genes in GDB, validating both observations. This project has resulted in the mapping of over $\mathbf{5 0}$ new genes with database matches. This includes new members of oncogene families, extracellular matrix proteins, establishment of an amyloid protein precursor family, etc.

\section{Specific Project}

Collaborations with numerous groups involved in both basic and medical research, have resulted in the mapping of 3 new sodium channel genes (Ingram/ Malo, MIT), four new genes of the cytosol and mitochondrion associated with folate metabolism (Shane, UC Berkeley), three new potassium channel genes (Chandy, UC Irvine), 3 extracellular matrix genes expressed in cartilage and bone (Roughly, Montreal), two new extracellular matrix genes expressed in the heart (Argraves, Washington DC), a human and rat homolog of the Dros. large discs tumor suppressor gene family (Kennedy, Caltech; Grandy, UCSD), and two new genes involved in thymocyte activation (Wall, Denny, UCLA).

Cross-Species Hybridization: We note that, with homology over approx. $88 \%$ at the nt level, Cross specific hybridization is now possible.

\section{Validity of FISH for accurate mapping of cDNAs: Multigene families and pseudogene families.}

In order to establish the validity of FISH for detecting the site of origin of a transcribed gene, data were generated to show that all locations of genes with previous information were confirmed and, in most cases greatly refined (by 5-40 Mb). Moreover, experiments revealed that the transcribed locus was detected in a significantly greater proportion of cells in both multigene families (G-proteins, Wilkie and Simon; Caltech) and for genes associated with large families of processed pseudogenes (Korenberg and Chen).

\section{Implications for Human Gene Disease Mapping.}

The somewhat surprising validation of FISH for cDNA mapping provides the basis for accurate determination of a human cDNA map at 2-3 $\mathrm{Mb}$ resolution within a short time period that is dependent only on funding and on the existence of high quality DNA from sequenced 3 ' cDNAs to limit redundancy. By providing immediate entree to a significant proportion of the genes mapping within a defined region of linkage, the provision of such a whole genome resource would greatly facilitate the rate of human disease gene definition. This could be provided as an immediate resource to the large and growing number of "cottage industry" basic and medical scientists who, with access to whole genome PCR-based markers, can now map genetic disease. 
B. Small Fragment mapping; non-cDNA.

1. A Physical \& Genetic map of the Chromosome 2 Centromeric region.

This pilot was undertaken in order to determine the feasibility of using FISH with small polymorphic markers to link physical maps with genetic maps at the 2-3 Mb level. Using 9 markers, 5 with known genetic order, and 4 located only by group, a high resolution map of the centromeric region of chromosome 2 was constructed by direct FISH mapping of fragments, most within the $1-3 \mathrm{~kb}$ range. All 9 were unambiguously ordered and the relationship to the genetic map obtained. The results showed that there is no disturbance of meiotic crossing over either at the centromeric region or at the region of the likely telomeric fusion occurring on $2 q 13$ that occurred between Chimpanzee and Humans. Further, the results of this study rapidly determined the correct direction for a gene disease associated a genomic walk. (Collaboration D. Cohn lab, UCLA; CSMC). This demonstrated the usefulness of rapidly linking physical and genetic maps using direct FISH of highly informative sequences.

\section{Genethon YAC Evaluation}

In order to evaluate the usefulness of this YAC resource for the community, in particular as a cDNA recognition source, about 40 YACs from the chromosome 21 MegaYAC array have been evaluated for map position and potential chimerism. The preliminary results indicate a persisting high rate of chimerism (Approx. greater than $30 \%$ ), and, as may be expected, with many primary signals located on chromosomes other than 21. Most positions were correct at this level of resolution. However, somewhat unexpectedly, the results indicate the existence and location of regions of homology located elsewhere on $21 \mathrm{q}$ and on chromosome 13q. The consistency of such regions identified, suggests that they are not the artifactual results of YAC chimerisim. (Collaboration Chumakov and Cohen, Genethon).

\section{NOVEL TECHNOLOGY}

Techniques designed to increase sensitivity and throughout are under development. These includes transfer of some aspects of sequencing technologies (Studier; SSB), previously tested to cDNA mapping; multiplexing, novel direct labels, etc.

Transportability of technology. The past 6 months has demonstrated the robust quality of the technology developed. The ability to both band chromosomes at high resolution and to map cDNAs with FISH rapidly, in the $2 \mathrm{~kb}$ range has been successfully taught to the technical staff of the Gatewood Lab (Los Alamos National Lab)

\section{GOALS FOR YEAR 2}

The major goals for year 2 include increasing the throughput by $2-3$ fold from that initially predicted (to $400-500 / y e a r / F T E$ ), in part by utilizing the image analysis system and in part by the application of technical advances developed this year. With the new recruitments, higher output of novel techniques is expected. It is expected that rapid methods for database screening will be defined. Finally, in view of the existence of increasingly efficient methods for genome searches based on tri and tetranucleotide markers, we may expect a sudden increase in the number of disease genes localized to regions of 3-10 Mb. Therefore, it is desirable to develop a means for providing rapid access to regional cDNA information. This will be delineated.

\section{DISCLAIMER}

\footnotetext{
This report was prepared as an account of work sponsored by an agency of the United States Government. Neither the United States Government nor any agency thereof, nor any of their employees, makes any warranty, express or implied, or assumes any legal liability or responsibility for the accuracy, completeness, or usefulness of any information, apparatus, product, or process disclosed, or represents that its use would not infringe privately owned rights. Reference herein to any specific commercial product, process, or service by trade name, trademark, manufacturer, or otherwise does not necessarily constitute or imply its endorsement, recommendation, or favoring by the United States Government or any agency thereof. The views and opinions of authors expressed herein do not necessarily state or reflect those of the United States Government or any agency thereof.
} 


\section{REFERENCES:}

Wilkie TM, Gilbert DJ, Olsen AS, Chen XN, Amatruda TT, Korenberg JR, Trask BJ, de Jong P, Reed RR, Simon MI, Jenkins NA, Copeland NG (1992) Chromosomal evolution of the $G$ protein alpha subunit multigene family. Nature Genetics 1:85-91.

Wood WJ, Thompson AA, Korenberg JR, Chen XN, May W, Wall R, Denny CT (1992) Isolation and chromosomal mapping of the human B29 gene. Genomics, in press.

Korenberg JR, Chen XN, Doege K, Grover J, Roughley P (1992) Assignment of the human aggrecan gene to $15 \mathrm{q} 26$ using fluorescence in situ hybridization analysis. Genomics, in press.

Garrow TA, Brenner AA, Whitehead VA, Chen X-N, Duncan RG, Korenberg JR, Shane B (1993) Cloning of human cDNAs encoding mitochondial and cystolic serine hydroxymethyltransferases and chromosomal localization. J. Biol. Chem, in press.

Korenberg JR, Chen XN (1992) Human gene mapping with cDNAs using fluorescence in situ hybridization, in preparation.

Korenberg JR, Chen XN (1992) Human gene mapping for mortals: Assignment of DNA sequences to single chromosome bands using fluorescence in situ hybridization. In preparation.

Korenberg JR, X-N Chen: Human cDNA mapping using fluorescence in situ hybridization. Abstract submitted to the 3rd International Workshop on Chromosome 21, Baltimore (1992).

Korenberg JR, Chen XN, Venter JC, Adams MD: Human cDNA mapping using fluorescence in situ hybridization. Poster. American Journal of Human Genetics 51:A78(1992).

Korenberg JR, Chen XN, Adams M, Venter JC: Human cDNA mapping using fluorescence in situ hybridization. US Department of Energy Human Genome Program. Contractur and Grantee Workshop III, p. 157. Feb. 1993.

Birren BW, Tachi-iri Y, Kim UJ, Korenberg JR, Shizuya H, Simon M: Genome composition and chromosome 22: Analysis of 96 mapped fosmids. US Department of Energy Human Genome Program. Contractor and Grantee Workshop III, p. 119, Feb. 1993.

Denison K, Gatewood JM, Korenberg JR, X-N Chen: Chromosomal localization of active genes. US Department of Energy Human Genome Program. Contractor and Grantee Workshop III, p. 198, Feb. 1993. 

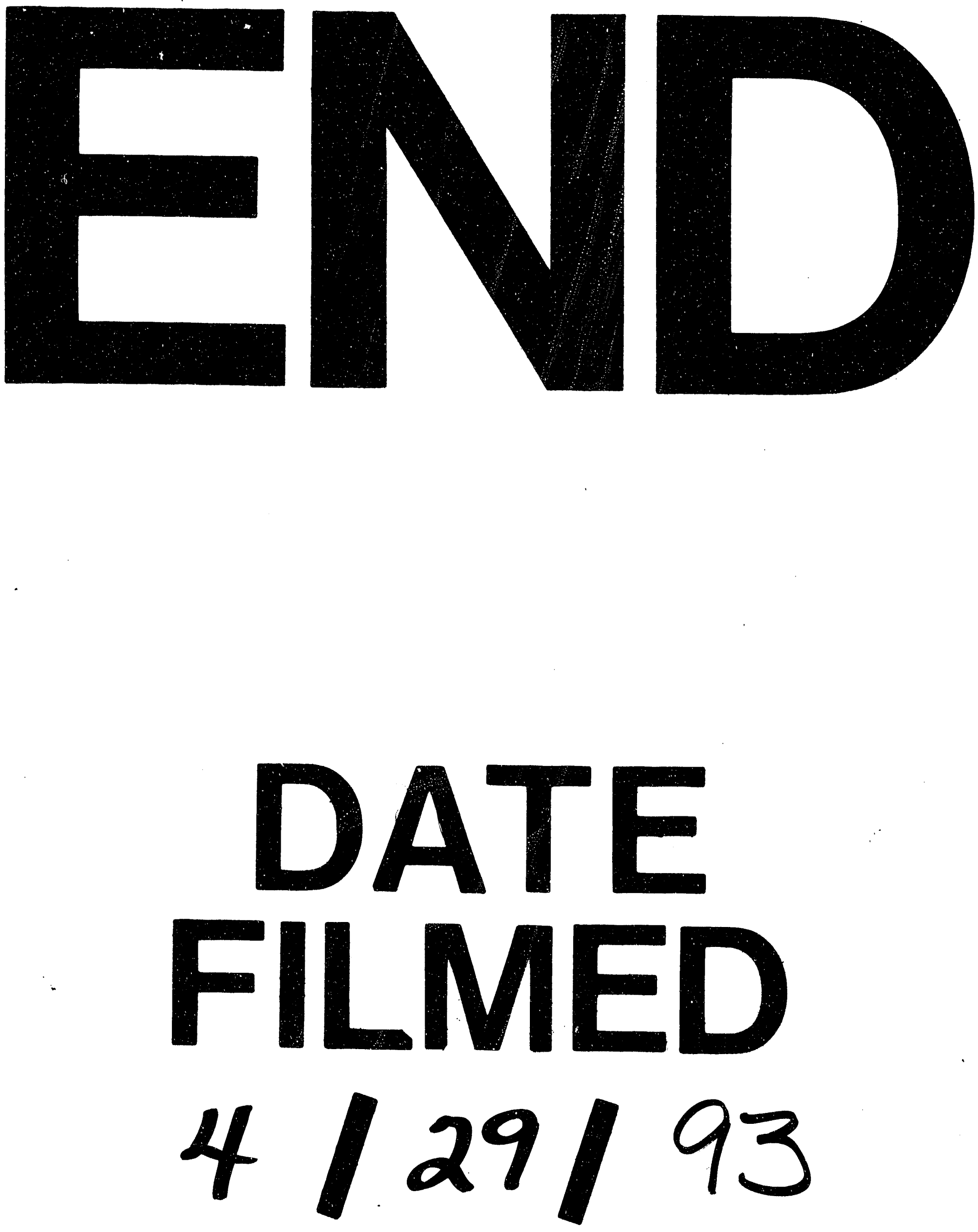
